\title{
Hemoclip retained for more than 2 years
}

The use of hemostatic clips in interventional endoscopic procedures is a common practice by endoscopists worldwide. We present here a case of clips at the cardioesophageal junction being retained for more than 2 years (27 months).

A 37-year-old man presented in September 2011 with heartburn, nausea, and occasional mild dysphagia to solid foods. He had undergone upper endoscopy in December 2009, 18 months earlier, when three metallic clips (Standard Clip 2951; Olympus Medical Corp., Tokyo, Japan) had been applied upon diagnosis of a deep Mallory-Weiss tear. His physical examination was unremarkable, and the results of routine blood tests were within normal limits. Upper endoscopy in September 2011 revealed two clips near the cardioesophageal junction ( Fig. 1). In February 2012, upper endoscopy showed one clip; the second clip had detached spontaneously ( $\bullet$ Fig. 2 and $\bullet$ Fig. 3 ).

Hemoclips are not magnetic resonance imaging (MRI)-safe, and are contraindications to MRI $[1,2]$. The average time that clips remain in place was reported as 9.4 days in the Olympus product insert and manual. It has been widely accepted that endoscopic clips detach within a 2-week period [3]. Due to the short retention time of the clips, health personnel usually forget to advise patients to abstain from diagnostic procedures that are contraindicated with a stainless-steel hemoclip in place, such as MRI. However, a clip can still be retained at 2 years, as reported in one case [3]. Our case showed that a clip can be retained even longer, for 2 years and 3 months. We found only one study that specifically looked at the length of time for which clips were retained and the prevalence of clip retention in humans [4]. In a retrospective study, 3 of 22 patients $(13.6 \%)$ had retained clips for a much longer period than expected. In these 3 patients, clips were still attached 4 weeks, 8 weeks and 3 months after insertion.

The increased use of hemostatic clips raises a safety issue that should be addressed. It may be appropriate that an abdominal radiograph should be done before an MRI scan for all patients with a history of clip deployment, to detect retained clips.

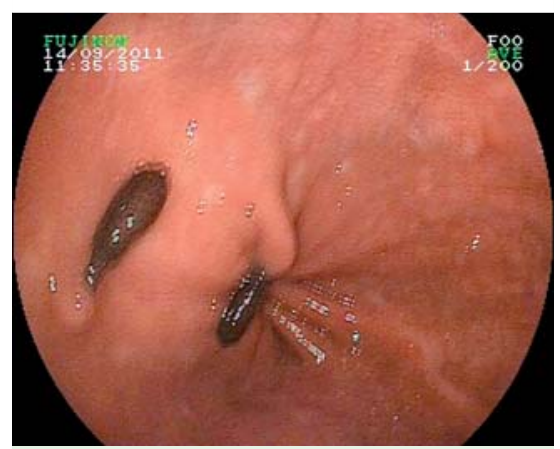

Fig. 1 Retained hemostatic clips near the cardioesophageal junction, seen in upper endoscopy.

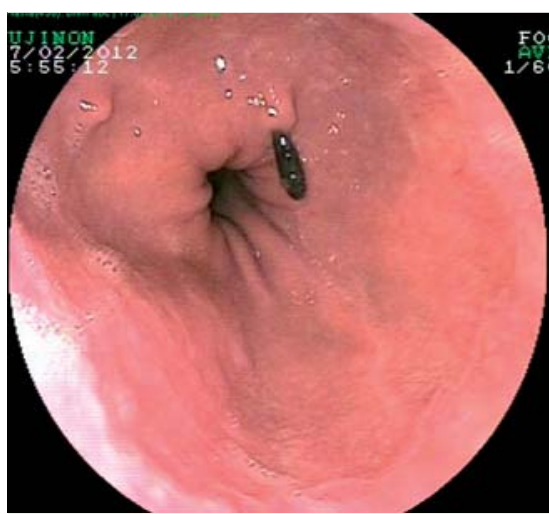

Fig. 2 The retained clip, at later upper endoscopy.

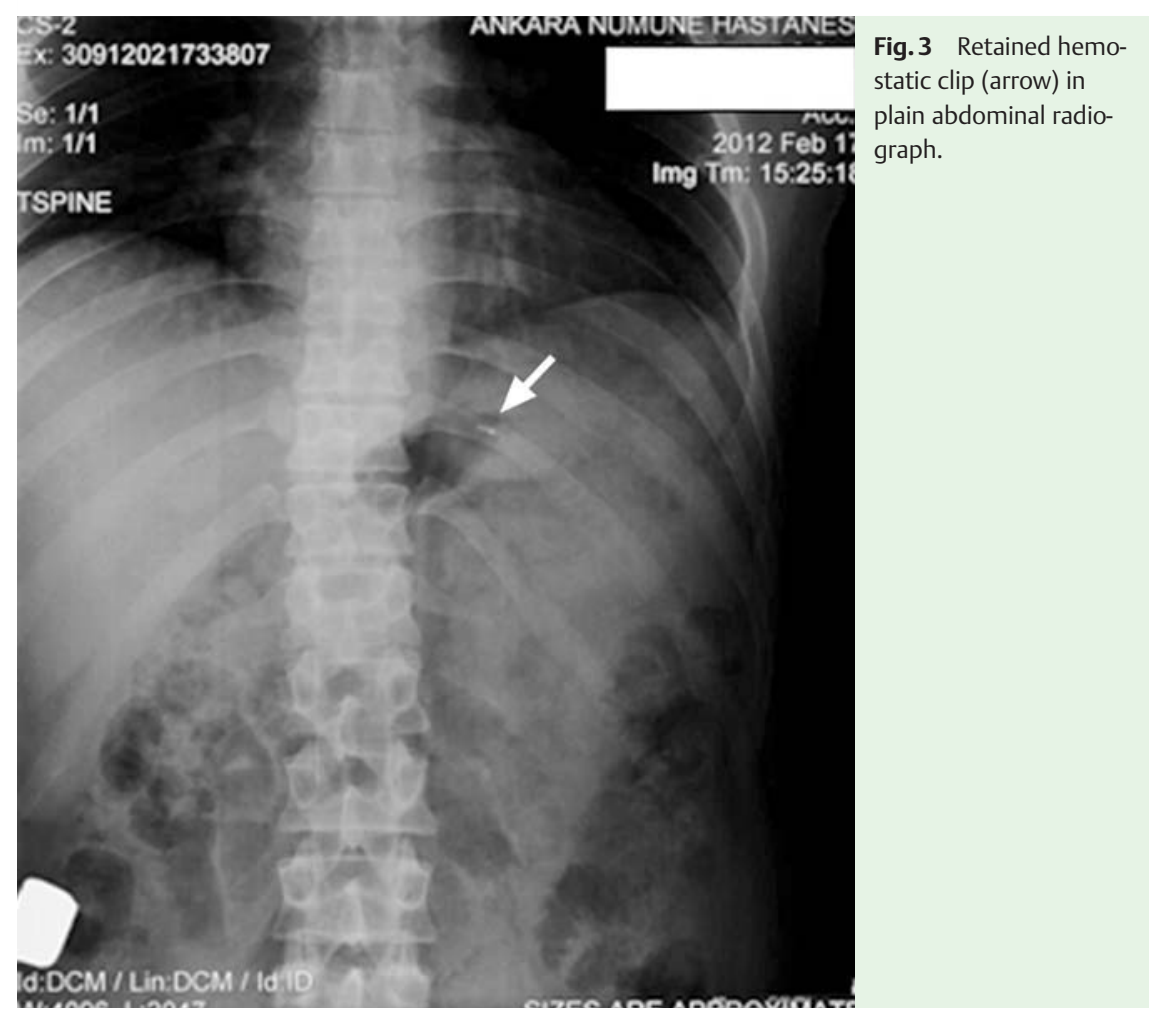

In a case of clipping during endoscopy, the endoscopist should inform the patient about the clip placement, and if an MRI scan is planned in a future hospital visit, the patient should remind the health personnel to obtain a plain abdominal radiograph before MRI.

Endoscopy_UCTN_Code_CCL_1AB_2AC_3AH

Competing interests: None

\section{S. Olmez, E. Ozaslan, U. Avcioglu}

Numune Education and Research Hospital, Department of Gastroenterology, Ankara, Turkey 


\section{References}

1 Kanal E, Barkovich AJ, Bell $C$ et al. ACR guidance document for safe MR practices: 2007. Am J Roentgenol 2007; 188: 1447 1474

2 Shellock FG, Spinazzi A. MRI safety update 2008: part 2, screening patients for MRI. Am J Roentgenol 2008; 191: 1140-1149

3 Ooi BP, Hassan MR, Kiew KK et al. Case report of a hemostatic clip being retained for 2 years after deployment. Gastrointest Endosc 2010; 72: 1315-1316

4 Volfson A, McKinley MJ. Prolonged endoclip retention time. Gastrointest Endosc 2011; 74: $727-728$

\section{Bibliography}

Dol http://dx.doi.org/

10.1055/s-0032-1309853

Endoscopy 2012; 44: E323-E324

(c) Georg Thieme Verlag KG

Stuttgart · New York

ISSN 0013-726X
Corresponding author

\section{E. Ozaslan, MD}

Cukurambar Mah. 1429, Cad. 24/2

Cankaya

Ankara

Turkey

Fax: +90-312-3125026

er72@hotmail.com 